\section{A liberdade do ser em Leibniz}

\section{Fabrício Fernandes Armond*}

Resumo: Neste artigo examinaremos como Leibniz estabelece uma noção de liberdade capaz de não entrar em contradição com a concepção de um mundo em que todos os acontecimentos sejam pré-determinados. Para tanto, veremos como Leibniz é capaz de dissolver a oposição entre a determinação e a contingência dos acontecimentos apoiandose na noção de ser, sobretudo ao sublinhar o seu caráter ativo. Veremos ainda alguns aspectos em que esta proposta leibniziana contrapõe-se ao dualismo substancial cartesiano e visa superar impasses que daí resultam tanto para a física, pela total passividade da substância extensa, como para a metafísica, sobretudo nos aspectos em que a substância pensante adquire feições de mera negação da substância extensa, o que levará a uma concepção da vontade como pura arbitrariedade, incapaz de ser regulada por qualquer princípio, e do entendimento como mero instrumento a serviço dessa arbitrariedade.

Palavras-chave: contingência, vontade, ser, onipotência, forma.

$\mathrm{Na}$ idade moderna os pensadores deparam-se com a perspectiva da matematização do universo. A possibilidade de explicar o real pelo recurso exclusivo à causalidade eficiente, que desponta com a nova mecânica, aponta para a concepção de um mundo regulado por necessidade geométrica, o que traz à tona o que chamaremos de problema da liberdade: como pode haver liberdade em uma natureza que funciona por causas necessárias? Neste texto, examinaremos como Leibniz confronta este problema. Procuraremos ver como ele, por meio da noção de ser, elimina a validade da noção de indeterminação e, ao mesmo tempo, defende a existência da liberdade em Deus e no homem. Concomitantemente, procuraremos estabelecer uma relação dessa operação com as bases da metafísica moderna em Descartes, referência e alvo constante das formulações de Leibniz em seu Discurso de Metafísica, de 1686.

Nosso percurso começará pela física. Por um lado, esse começo nos permitirá partir daquele solo de onde brota a formulação moderna do problema da liberdade. Mas,

* Aluno de graduação do Departamento de Filosofia da USP. por outro, e mais fundamentalmente aqui, o objeto da física, tal como considerado por Leibniz, nos mostrará que a substância, ou, de forma mais geral, o ser, deve manifestarse como uma forma de ação, que deixa transparecer um princípio que o unifica e torna idêntico. Este ponto será retomado posteriormente ao discutirmos a noção de vontade em Leibniz, e será ele o "elo" que permitirá conciliar a contingência e a determinação dos acontecimentos. Se tal formulação também se encontra em enunciados puramente metafísicos de Leibniz, a exposição a partir da física tem a vantagem de nos deixar ver mais claramente a insustentabilidade da noção de substância como mera passividade, como no caso da substância extensa de Descartes, além de aludir à dissolução das dicotomias cartesianas por Leibniz, ponto que, no entanto, não aprofundaremos. A partir daí, já de posse da noção de forma de ação, passaremos a uma descrição esquemática da mônada e de sua gênese em Deus, que nos levará ao problema da incompatibilidade entre um mundo que deve exprimir a bondade de Deus e onde, ao mesmo tempo, não deve haver contingência. Passando pela polêmica com Arnauld, chegaremos então ao verdadeiro núcleo do problema da liberdade, que é o problema da existência ou não da vontade autônoma e, conseqüentemente, de um espírito ontologicamente autônomo, que não se reduza a mero fenômeno resultante da causalidade física. Assim, tendo em vista o problema da liberdade como o problema da existência do espírito, abordaremos relações entre a vontade e o entendimento que são suscitadas pelas diferentes concepções de vontade dos dois filósofos, e poderemos rapidamente explorá-las tanto em relação ao homem quanto a Deus. Isso nos permitirá abordar criticamente alguns pontos da metafísica cartesiana a partir das colocações de Leibniz, notadamente: a maneira como a concepção de vontade em Descartes leva a um choque entre a arbitrariedade divina e a possibilidade de garantir a correspondência entre as idéias do sujeito e os objetos que elas representam; a arbitrariedade como uma vontade "descolada" do ser do agente; a subordinação da onisciência à onipotência de Deus. No fim desse percurso procuraremos ter mostrado que o principal resultado da operação com que Leibniz dissolve a oposição entre a contingência e a determinação é o desmantelamento da noção de vontade como arbitrariedade pura, que não se orienta por um princípio racional. 


\section{Contingência e liberdade}

A ação livre é a ação voluntária. A noção de ação voluntária supõe a de contingência, ou de um "espaço de indeterminação" em dois pólos: no mundo e no agente. Se o mundo é completamente determinado por leis necessárias, não há “espaço de ação" para o agente. E se o agente é a fonte de onde brota a ação voluntária, ele não pode estar submetido à necessidade deste regime de causalidade, não podendo dissolver-se no mundo.

A subjetividade como concebida por Descartes pôde, até certo ponto, contornar este problema. A irredutibilidade da consciência, demonstrada em suas duas primeiras meditações, indicaria a autonomia do sujeito em relação ao mundo físico e, portanto, a existência de duas substâncias: a extensa e a pensante (Descartes 1). Se os estados da substância pensante não são determinados por nada exterior, a substância extensa, por outro lado, é passiva e submetida à necessidade geométrica, constituindo o campo da objetividade.

Essa solução levantará dois problemas que Leibniz pretenderá ter superado com uma concepção de substância que rejeita a dualidade substancial cartesiana. Primeiro: como se dá a interação entre essas duas substâncias? Segundo: como se explica que a modificação dos estados de algo não tenham uma causa exterior?

\section{Ação: forma de ser e forma do ser}

Em seus escritos, Leibniz proporciona mais de uma via para se chegar a essa sua concepção de substância. Um acesso a partir de sua física pode ser encontrado entre os parágrafos 17 e 22 de seu Discurso de Metafísica. No parágrafo 21 ele conclui que, "se no corpo nada houvesse além de massa extensa, e no movimento senão mudança de lugar, e se tudo devesse e pudesse deduzir-se exclusivamente dessas definições por necessidade geométrica [...] o corpo menor daria ao maior, que encontrasse e que estivesse em repouso, a mesma velocidade que tem, sem qualquer perda da sua própria” (Leibniz 3, §21, p.138). Descartes estabelece que a substância do mundo físico é a extensão. Esvaziada de qualquer qualidade adicional, essa substância extensa só admite dois estados: o movimento e o repouso. Como o vácuo não é possível, já que entre dois corpos quaisquer sempre é possível mensurar a extensão que os separa, esse movimento é o movimento da própria extensão. Daí que Leibniz conclua que quando um intervalo extenso muda sua posição, ele necessariamente tem que deslocar ao mesmo tempo uma extensão equivalente a essa mudança. Se a velocidade é a medida deste deslocamento num tempo determinado, consideremos dois intervalos extensos contíguos, corpo 1 e corpo 2 . Se o corpo 1 desloca determinado espaço num determinado intervalo de tempo, o corpo 2, a ele contíguo, não importando o seu tamanho, será deslocado na mesma distância que o corpo 1, dentro do mesmo intervalo de tempo, ou seja, o corpo 2 adquirirá a mesma velocidade do corpo 1 . Daí que se o mundo físico for composto somente de extensão, um corpo menor deverá transmitir a um maior a mesma velocidade que tem, sem qualquer perda de sua própria.

Também por isso Leibniz, no mesmo parágrafo, afirma que a partir da física de Descartes somos obrigados a admitir regras "absolutamente contrárias à formação dum sistema" (Leibniz 3, §21, p.138), já que a própria noção de corpo torna-se um problema a partir da conclusão acima. Se a velocidade é igualmente transmitida independentemente das características dos corpos, o movimento nesse universo é uma reação em cadeia, e todo o universo move-se uniformemente. Em outras palavras, se o universo é uma massa extensa, suas partes não diferem de sua totalidade e umas das outras a não ser pelo seu tamanho. Ao não possuírem nenhuma propriedade que possa delimitá-las dentro do todo, já que são somente extensão, como todo o resto, essas partes não podem apresentar um comportamento definido, sendo completamente passivas e indiferenciadas. Sendo indiferenciadas, elas dissolvem-se na totalidade, já que não possuem dentro de si um princípio de unificação que as delimite de tudo o mais. Assim, neste universo as próprias noções de todo e partes tornam-se inviáveis e, com isso, a noção de sistema, que se define justamente pela interdependência entre o todo e suas partes: partes que aqui não podem ser isoladas, sendo infinitamente divisíveis. Desaparecendo as noções de todo, partes e sistema, desaparece a de corpo, que não designa nada de definido, a não ser uma parcela arbitrária de extensão. O que nos leva a duas questões: se a palavra corpo não designa nada de definido, qual a validade de definir relações entre corpos?; e se nem mesmo é possível delimitar um corpo, ou uma unidade qualquer dentro da totalidade do universo físico, como determinar que há movimento ou qualquer comportamento, tanto das partes 
como do todo, se não é possível observar qualquer relação entre partes, já que não há partes em sentido estrito? Em um universo completamente homogêneo, nem os corpos nem os movimentos seriam possíveis.

Daí a importância da força na física leibniziana, contraposta à quantidade de movimento, cuja distinção é demonstrada por Leibniz no parágrafo 17 do Discurso de Metafisica (Leibniz 3, p.132-134). A força determina, no duplo sentido de que é um princípio de ação e de que delimita o agente, que, como princípio de ação, não se perde na total indistinção com todas as outras coisas. Por isso a identificação da força, na física, com a substância: ela define o ente físico ao unificá-lo. É seu comportamento padronizado, com um sentido, que torna o ente idêntico a si mesmo e o recorta do restante do mundo. É então a unidade com esse comportamento padronizado que será a verdadeira substância, e a força, na verdade, será a manifestação física de uma realidade metafísica - a substância. Qualquer comportamento com um sentido manifesta uma unidade mais íntima, o que permitirá a Leibniz concluir pela existência de finalidades na própria natureza no parágrafo 18 do mesmo Discurso de Metafísica (Leibniz 3, p. 134 -135). O que nos interessará na continuação da discussão sobre a liberdade é que o princípio que unifica os seres e permite sua identidade - que eles permaneçam sendo eles mesmos - é um determinado modo de ação, ou seja, um comportamento padronizado, passível de delimitação: a forma de agir manifesta a forma de ser.

\section{A Mônada: a história como desdobramento de um princípio}

Mônada é a designação de Leibniz para essa substância. Pelo exposto acima, ela é uma entidade formal. Desde os antigos a forma designa o que é idêntico nos entes. Entre elas, portanto, não resta espaço para a ação voluntária - elas não podem receber de um agente uma outra determinação além da que já as caracteriza como formas. A ação voluntária só é possível devido à matéria, que, sendo o princípio caótico nos entes, é unificada pela forma, mas nunca completamente: sempre resta uma inadequação dela com a forma, por onde se insinua o movimento e a contingência, da qual depende a ação livre. Disso concluiríamos que na natureza deve haver algo, diverso das mônadas, que possa cumprir um papel análogo ao da matéria. Leibniz, no entanto, não reabilita tal concepção e defende que o mundo é composto somente pelas mônadas, sendo completamente determinado. Isso nos levaria a concluir que no mundo não deve haver liberdade, já que ela pressupõe a contingência. Mas, para Leibniz, determinação não é sinônimo de necessidade e, por isso, é possível conciliar contingência e determinação. Essa operação, por sua vez, será possível devido à maneira com que Leibniz, diferentemente de Descartes, concebe a onisciência de Deus.

Para Leibniz "as Mônadas são os verdadeiros Átomos da Natureza" (Leibniz 4, $\S 3$, p.105). Isso implica que elas não têm extensão nem partes (a extensão é infinitamente divisível), não podendo ser formadas por composição, nem destruídas por desagregação (Leibniz 4, §§4-5, p.105). Por isso, mesmo que atuem como princípios de ação, precisam ter vindo à existência por uma causa exterior a elas. Essa causa, por outro lado, sendo a origem de todo o ser, deve concentrá-lo em si de forma totalmente incondicionada, de modo a ter em si mesma o princípio de sua própria existência - do contrário teria de haver uma cadeia causal infinita (Leibniz 4, §§37-38, p.109). Conforme Leibniz, "Esta suprema substância única, universal e necessária, sem nada de externo independente dela, e simples resultado de sua possibilidade, pode também julgar-se que não é suscetível de limites e que contém o máximo possível de realidade" (Leibniz 4, §40, p.109). Essa substância é Deus.

A perfeição absoluta de Deus deve conter todas as formas do ser em grau último, como o poder, a ciência e a bondade (Leibniz 3, §§1-2, p.119), cujos contrários designam formas do não ser. Como o mundo é criação de Deus, ele deve conter essas formas do ser de Deus, embora de modo limitado. Assim, se consideramos que no mundo existe o mal, o que há na verdade é a limitação do bem. Por outro lado, Deus não cria arbitrariamente o mal porque, sendo infinitamente bom, deve necessariamente criar o melhor dos mundos possíveis. Aqui está a raiz da mônada. Se o mal é o não ser, tanto melhor será o mundo quanto maior o grau de realidade que ele contiver ${ }^{1}$. A fórmula dessa diretriz é o maior número de efeitos para o menor número de princípios (Leibniz 3, §5, p.122), de modo que este mundo deverá concentrar o maior grau de realidade possível em suas menores unidades. No melhor dos mundos, então, se equaciona o maior grau de ser pelas vias mais simples. O ser mais simples, por sua vez, é o espiritual, que em sua unidade e simplicidade é capaz de conter uma multiplicidade infinita de percepções. O 
melhor dos mundos contém infinitas unidades espirituais - as mônadas - que se percebem mutuamente. Dentro de cada uma delas espelha-se o infinito das demais mônadas, com o infinito de suas percepções - infinito vezes infinito vezes infinito...- tendo-se o máximo possível de realidade desdobrando-se de dentro das substâncias mais simples, que não deixam, entretanto, de ser unidades reais:

"toda substância é como um mundo completo e como um espelho de Deus, ou melhor, de todo universo, expresso por cada uma à sua maneira, pouco mais ou menos como uma mesma cidade é representada diversamente conforme as diferentes situações daquele que olha. Assim, de certo modo, o universo é multiplicado tantas vezes quantas substâncias houver, e a glória de Deus igualmente multiplicada por todas essas representações de sua obra completamente diferentes" (Leibniz 3, §9, p.125).

Mas, se as mônadas são princípios de percepção, temos dois problemas: 1) o que é o espaço e como as mônadas se manifestam nele como força? ; 2) como as mônadas afetam umas às outras e têm acesso às percepções umas das outras?

Não seria possível desenvolver aqui todas essas respostas. Para nosso intento, importa saber que as mônadas não interagem diretamente. Todas as percepções de cada uma delas desdobram-se delas mesmas e nenhuma mônada é diretamente afetada por outra. A harmonia entre todas elas é estabelecida por Deus (Leibniz 3, §14, p.129-131). Por outro lado, para Leibniz o espaço não tem autonomia substancial alguma. A percepção das relações espaciais não passa de uma percepção confusa das verdadeiras relações entre as substâncias individuais, confusão implicada pela limitação de seu "ponto de vista" (Leibniz 3, §12, p.127), e o princípio interno que induz à mudança nas percepções é o que se manifesta na percepção do mundo físico como força, e que não deixa de ser o princípio que unifica, dá sentido e caracteriza os entes, como a própria força em relação à extensão.

As mônadas não são constantemente reguladas e munidas de percepções por Deus. O ser delas é o princípio de sua ação, ou seja, suas percepções desdobram-se de dentro delas mesmas (Leibniz 4, §11, p.106), já tendo sido efetivadas por Deus desde sempre com a finalidade de estabelecer o melhor dos mundos. Assim, cada mônada, como substância individual, já traz dentro de si tudo que lhe acontecerá (Leibniz 3, §9, p.125). Pensemos em um homem: Adão, por exemplo. Ele é constituído de infinitas mônadas, uma das quais sobressairá em nitidez de percepção entre todas, constituindo o que entendemos por seu espírito. Desde sempre, tudo que acontecerá a Adão já está inscrito em sua noção individual. E, com isso, todos acontecimentos de todo universo também estão inscritos nessa mônada.

A partir daqui se assinalaria o fim da contingência e também da liberdade, que pode ser sublinhado em dois pontos gerais: porque suas ações já estão predeterminadas, o homem não é livre; e porque necessariamente deve criar o melhor dos mundos, Deus não é livre (Leibniz 3, §3, p.120). Se a ausência da liberdade no homem contradiz nossa experiência e traz impasses éticos pelo fim da noção de responsabilidade, além de estabelecer uma dificuldade lógica para se conceber a conciliação de um universo sem liberdade e a infinita bondade de Deus, a ausência de liberdade em Deus leva a um absurdo lógico pela eliminação da Sua onipotência.

\section{Vontade e possibilidades: crítica à mônada a partir de uma perspectiva cartesiana}

Tais dificuldades demonstrariam a impossibilidade de a substância individual de Leibniz superar a metafísica de Descartes (onde Deus também figura como o ser perfeito). Ao discutir com Leibniz o Discurso de Metafísica, Arnauld, que compartilha das posições cartesianas, constrói seus argumentos a partir da proposição: “que a noção individual de cada pessoa encerra de uma vez por todas o que lhe acontecerá em qualquer tempo" (Arnauld in Leibniz 6, p.88), donde ele conclui: "tudo o que aconteceu ao gênero humano, e para sempre lhe acontecerá, deveu e deve acontecer com uma necessidade mais do que fatal" (Arnauld in Leibniz 6, p.88). Os desdobramentos iniciais dessa observação de Arnauld são: 1) Deus é livre para criar, mas não é livre (não tem poder) para interferir no curso do que foi criado; 2) o homem não é livre.

O primeiro desdobramento não oferece dificuldade: sendo Deus onisciente, previu todas as conseqüências do ato da criação. Interferir em seu curso só poderia depor 
contra Sua onisciência (Leibniz 6, p.76). Mas é a partir daqui que Arnauld aprofundará a discussão e atacará uma das noções chave da metafísica leibniziana: a de possibilidades. Ela é implicada pela de melhor dos mundos, donde se pressupõe uma escolha de Deus entre outro ou outros mundos possíveis.

Arnauld inicia sua argumentação questionando "se não é senão em conseqüência dos Decretos livres, pelos quais Deus ordenou tudo o que aconteceria a Adão e a sua posteridade, que Deus conheceu tudo isto, ou se há (independentemente destes decretos) entre Adão, por um lado, e o que aconteceu e acontecerá a si e a sua posteridade, por outro, uma conexão intrínseca e necessária" (Arnauld in Leibniz 6, p.90). Ou seja, Arnauld põe em questão se, antes da criação por Deus, haveria uma noção lógica de Adão que contivesse tudo que aconteceria tanto a ele como a toda a sua descendência. Considerando que essa é a posição de Leibniz, continua: “creio que supondes [...] que as coisas possíveis são possíveis antes de todos os Decretos livres de Deus: donde se segue que aquilo que está encerrado na noção das coisas possíveis, aí se encerra independentemente de todos os Decretos livres de Deus. [...] Segundo vós há, portanto, uma ligação por assim dizer intrínseca e independente de todos Decretos livres de Deus entre este Adão possível e todas pessoas individuais e toda sua posteridade - e não só as pessoas, mas tudo que deve acontecer-lhes de modo geral" (Arnauld in Leibniz 6, p.90). O que Arnauld questiona, portanto, é a independência da possibilidade em relação a Deus, o criador de tudo. Tal existência, no final, acabaria por contradizer a onipotência divina.

Para Arnauld, a possibilidade de existência supõe a vontade de Deus. E assim não há ciência possível de algo que não possa existir:

“Acaso podemos conceber [...] que embora a ciência de Deus seja sua própria essência [...], que ele tenha, porém, a ciência de uma infinidade de coisas que poderia não ter, se não pudessem existir tais coisas? O mesmo se dá com sua vontade, que é também sua própria essência, onde tudo é necessário. Entretanto Deus quer e quis desde toda a eternidade coisas que poderia não querer. Vejo muita incerteza na maneira pela qual comumente representamos as ações de Deus. Imaginamos que antes de querer criar o mundo encarou uma infinidade de coisas possíveis, escolheu algumas e rejeitou outras [...]. Sou forçado a crer que não passam de quimeras que nós formamos, e as chamadas substâncias possíveis, puramente possíveis, não podem ser outra coisa senão a onipotência de Deus, que, como ato puro, não tolera em si nenhuma possibilidade. Todavia podemos concebê-la nas naturezas que criou, pois, não sendo em essência o próprio ser, são necessariamente compostas de potência e ato [...]. Quanto a mim estou convencido de que, embora falemos tanto destas substâncias puramente possíveis, jamais concebemos qualquer uma que não derive da idéia de outra criada por Deus" (Arnauld in Leibniz 6, p.90).

Dentro da perspectiva cartesiana, Arnauld defende que, antes da criação, Deus é tudo o que há. Seu poder é infinito. Por isso, Ele não tem necessidade ou obrigação alguma e por nada é afetado, sendo puramente ativo. Absolutamente livre, Sua ação é idêntica à Sua vontade (o atributo fundamental da substância pensante em Descartes, juntamente com o entendimento). Assim, a criação é um ato absolutamente original, no sentido mais forte desta expressão: Deus não cria somente tudo o que é, mas inaugura também a própria forma do ser, e tudo isso de acordo com a Sua vontade, já que o nada não tem potencial algum. Daí a total anterioridade, para Arnauld, dos Decretos livres de Deus em relação a qualquer possibilidade: uma possibilidade só pode se oferecer após a criação, e dentro dos limites estabelecidos por Deus.

Ao fim da argumentação de Arnauld temos, então, três problemas: 1) a noção de possibilidades contradiz a onipotência de Deus, pois postula que há noções lógicas independentes Dele; 2) Deus não é livre (portanto não é onipotente) porque é constrangido a criar o melhor mundo possível; 3 ) as decisões humanas estão pré-definidas, portanto o homem não é livre. Ou seja, além de forjar uma noção de possibilidades incompatível com uma perspectiva criacionista, Leibniz destruiria a contingência, submetendo Deus e o homem ao jugo das causas necessárias.

\section{Arbitrariedade divina e solipsismo}

Mas também no posicionamento cartesiano algo fica em aberto. A absoluta 
liberdade de Deus, que se manifesta pela completa insubmissão da vontade divina, é um ponto obscuro no pensamento de Descartes: os desígnios de Deus são incompreensíveis, neles se rejeita qualquer pretensão de conhecimento, entra-se no domínio do infinito, do que é incapaz de ser apreendido pela finitude humana. Em Descartes, com efeito, a lógica está constantemente sob ameaça: o gênio maligno é a imagem daquela desconfiança da razão que opera sob a forma da dúvida metódica, capaz de deixar a própria razão em suspensão até que a idéia de Deus possibilite a saída do círculo de ter que garantir a razão pelos mesmos conteúdos postos em dúvida pela impossibilidade de assegurá-la. Mas a questão é: até que ponto Descartes pôde livrar-se do gênio maligno admitindo tal concepção da vontade de Deus? Quando dissemos acima que a criação do mundo significa não só a criação dos seres, mas da própria forma do ser, dissemos que ali Deus estabelece todas as verdades, como Leibniz lembra a Arnauld: "Vejo que o Sr. Arnauld [...] não se preocupou com a opinião dos cartesianos, que sustentam que Deus estabelece por sua vontade as verdades eternas, como aquelas tocantes às propriedades da esfera" (Lebniz 6, p.100). Assim, por sua vontade, Deus poderia ter criado um universo em que o triângulo tivesse ângulos internos com soma diferente de $180^{\circ}$, assim como diferentes formas para o que é justo ou injusto, feio ou bonito, bom ou mau.

Na terceira meditação, após o exame de suas próprias idéias, Descartes conclui que a idéia de Deus leva à constatação de que Deus existe e é perfeito. Sendo perfeito, não poderia se preocupar em enganar o sujeito, já que a preocupação expressa uma carência, e Deus seria imperfeito. Disso ele conclui que a correspondência entre objetos e razões é possível e está garantida (Descartes 1, p.288-289). Mas o que permite a Descartes fazer essa ponte? Nesta linha de raciocínio, Deus também manifestaria uma preocupação e uma carência se procurasse garantir que os raciocínios humanos não fossem inerentemente falhos e correspondessem a objetos reais. A garantia, então, estaria numa constatação positiva: a clareza e distinção de certas verdades, como as matemáticas, por exemplo (Descartes 1, p.269-270). Assim, Deus poderia ter criado qualquer mundo, mas de fato criou um em que são possíveis a clareza e a distinção, o que constatamos empiricamente. Se a clareza e a distinção são dadas, o sujeito só poderia se enganar através de uma intenção de Deus, que manifestaria, então, uma carência. Deus, portanto, não é enganador e a objetividade é possível.
Examinando de perto este argumento, vemos que após concluir pela indestrutibilidade do cogito, Descartes deduz que se ele manifesta uma certeza, possuímos necessariamente os critérios da verdade, que são a clareza e a distinção (Descartes 1, p.269-270). Daí a possibilidade de Descartes manejar as idéias que apresentam clareza e distinção, entre elas a de Deus, e concluir seu raciocínio a fim de garantir a possibilidade da objetividade. Mas aqui fica uma questão: dentro da argumentação de Descartes é realmente possível transplantar a indestrutibilidade do cogito para os mesmos critérios de clareza e distinção que encontramos na matemática ou em outras idéias? Ora, se fosse realmente possível identificar a resistência do cogito com a das verdades matemáticas, por exemplo, qual seria a necessidade de se duvidar das matemáticas e de outras verdades equivalentes? Se a investigação de Descartes nas Meditações teve que prosseguir até o ponto de o cogito se apresentar como uma verdade primeira, é porque ele apresenta um grau certeza que as outras idéias não possuem, e as conclusões tiradas a partir delas, inclusive sobre o ser de Deus, continuam tão duvidosas quanto antes era duvidoso que a soma de 2 e 3 fosse 5 , de modo que o raciocínio deve permanecer paralisado e não pode concluir se é razoável supor qualquer coisa sobre Deus ou coisa alguma.

Assim, com a impossibilidade de se transplantar a certeza do cogito para outras razões, mesmo que admitíssemos que o raciocínio de Descartes acerca de Deus estivesse correto e considerássemos que Deus manifestaria uma carência ao se preocupar em enganar o sujeito, deveríamos novamente considerar que Deus manifestaria uma preocupação e, portanto uma carência, se ao criar o mundo se preocupasse em garantir que as representações do sujeito fossem corretas. Se a vontade de Deus é absolutamente livre, a nada se submetendo, e a forma do ser é totalmente delineada no momento da criação, nada impede que estejamos em um universo em que somente a certeza de si do sujeito possa ser garantida, já que, pelo que dissemos, nenhuma idéia ou raciocínio dispõe do mesmo grau de certeza que o cogito. Ou seja, se Deus é indiferente e pode criar qualquer mundo, por mais absurdo que se represente para nossa razão, a própria razão não pode ter critérios para avaliar a correspondência das idéias com objetos, já que nem mesmo a coerência interna do raciocínio estaria garantida. Assim, nas conclusões de Descartes, o círculo é deslocado, não dissipado: por um lado, a razão é garantida por Deus que, por outro, tira-lhe a potência. 


\section{A liberdade como exercício do ser: a vontade em Leibniz e sua oposição à arbitrariedade}

Entretanto, se com a permanência do cogito cartesiano nos está assegurada ao menos a validade do princípio de identidade, talvez possamos conceber a vontade divina de outra forma. Já dissemos que tanto para Leibniz como para Descartes Deus é absolutamente perfeito. Tem-se aqui uma definição. Mas essa fórmula até aqui não é suficiente para determinar o ser de Deus de forma a nos indicar qual partido tomar, ao menos aparentemente. Em Leibniz a vontade é determinada por um princípio fundado no ser de Deus, o que a torna eterna. Em Descartes a vontade não se submete a princípio algum e Deus pode mudar ou permanecer em seu desígnio. O que é, então, a vontade? Até aqui ela se evidencia como um princípio ou causa de movimento: é de acordo com ela que o poder de Deus tem o "impulso" para criar o mundo. Mas, tomada em si, a própria vontade é uma espécie de movimento: ela é uma disposição para algo, uma tendência que dirige um ser para algo. Ela é tender para algo. Essa tendência pode ser motivada por um objeto exterior, o que denota uma passividade. É o que conhecemos tradicionalmente por desejo. No desejo o ser é dividido: existe em si mesmo, mas se concentra em um outro, de modo que não está totalmente em si mesmo. Mas, se não está em si mesmo, tampouco está no outro; daí a necessidade de se dirigir a esse outro para tomar posse dele e, ao mesmo tempo, tomar posse de si mesmo, concentrado nesse outro. Em parte em si mesmo e em parte em direção a outro, o ser que deseja é um ser cindido. E assim, de certa forma, o ser que deseja se perde de si mesmo no objeto do desejo, o que acontece de uma forma tão radical que dirige seu ser para o outro como ato, que não se efetiva somente mediante alguma forma de resistência. Mais radical que uma passividade mecânica, que move algo "de fora", o desejo o move "por dentro", ao cindi-lo mesmo que momentaneamente ${ }^{2}$. Tal concepção naturalmente não pode ser aplicada a Deus, que não pode ser cindido em função de algo exterior para o qual ele tenha a necessidade de se dirigir para se completar. Haveria uma alternativa para se conceber a vontade? Uma vontade que não for desencadeada por algo exterior só pode provir do próprio ser. O que provém de um ser só pode concordar absolutamente com a sua natureza, ou seja, por um lado deve ser idêntico a essa natureza de modo a não poder contradizê-la, e, por outro, deve exprimi-la. Uma vontade que não for dirigida por um objeto deve, então, exprimir o ser do sujeito, a sua natureza. Ou seja, ela deve obedecer a um princípio, e não porque ela é constrangida a isso, mas porque ela é manifestação desse princípio e porque não pode ser nada diferente dele.

Ora, se essa vontade só pode ser a manifestação do ser, a genuína manifestação do ser é a própria vontade. Ela é a tendência natural que emana do próprio ser, e é idêntica a ele, não sendo nada mais que a afirmação desse ser em ato, o que é muito diferente de qualquer coisa que precise ser saciada por meio de um objeto qualquer, seja ele "real" ou "espiritual". Enquanto que no desejo algo é assimilado, na vontade ocorre o desdobramento de si; enquanto que no desejo é o objeto exterior que ressoa dentro de um sujeito, a vontade é nada menos que o ressoar desse ser no exterior. Se consideramos que o ser de Deus é idêntico (ou seja: que Deus não deixa de ser Deus), temos que considerar que sua vontade deve permanecer sempre a mesma, obedecendo ao princípio de Sua natureza. Se Deus é infinitamente bom, essa vontade deve exprimir essa bondade. Com efeito, conceber a vontade de outra forma - da forma cartesiana -, como algo que não precisa obedecer a qualquer padrão, só pode apontar para uma cisão dentro de Deus: de seu interior brotaria uma vontade que tem autonomia em relação a Ele (em relação à sua natureza), e Deus perderia sua perfeita unidade e identidade. De nada adiantaria dizer que essa vontade cartesiana é fundada na onipotência divina, pois se a onipotência é um poder tudo, essa vontade teria de ser uma vontade de tudo e assim uma efetivação de tudo - e poderíamos até incluir aí a vontade de nada, de modo a cair no absurdo de uma vontade de tudo e nada ao mesmo tempo. Dizer, por outro lado, com base na onipotência, que ela é uma espécie de autocontrole absoluto só remeteria infinitamente à questão: autocontrole para fazer o quê?, que demandaria novamente a vontade para fundamentar esse fazer.

Aplicando sobre a concepção cartesiana de vontade uma interpretação já clássica sobre a sua concepção de substância, poderíamos dizer que, da mesma forma que a substância pensante de Descartes é forjada pela negação dos atributos da substância extensa, a vontade cartesiana é uma espécie de negação do desejo. Entretanto, no fim das contas essa negação acaba por conduzir ao mesmo resultado do desejo, a quebra da unidade do ser, não passando de um desejo fantasmagórico. Por outro lado, a crença de que Deus, por seguir um princípio para sua ação (a bondade para a criação do melhor 
dos mundos), é constrangido e por isso não é livre, se mostra auto-contraditória, pois leva à conclusão de que Deus é obrigado por si mesmo, ou seja, de que é absolutamente livre. Tal equívoco parece se fundar numa confusão lingüística: na proposição "Deus deve criar o melhor dos mundos", tomar o verbo dever no sentido de imposição e não de desdobramento de si mesmo, ou seja, identidade. Prosseguir em tal equívoco levaria a considerar que são contraditórias proposições como "Deus deve ser onipotente", ou "Deus deve ser Ele mesmo".

Como na física, em que o princípio do movimento aponta para uma determinada forma de ser e à sua unidade, o que nos leva à conclusão de que sem um padrão de comportamento definido algo não manifesta um ser, a vontade deve ser idêntica, ou seja, ter um padrão determinado, obedecendo a um princípio. Do contrário, ela seria aleatória, não obedeceria a um padrão de comportamento, não manifestando uma forma de ser. Assim, ou ela mudaria sempre, não apresentando uma forma definida ou, se ela não mudasse, permaneceria a mesma por mero acaso.

Por isso, da definição de Deus como ser perfeito, que deve ser onipotente, acabamos por admitir que sua vontade deve regular-se por um princípio, como defende Leibniz. Princípio que deve ser a própria perfeição de Deus, que encerra a sua infinita bondade. Mas, dos três problemas que enunciamos, só o segundo parece estar resolvido: Deus não deixa de ser livre ao ter que criar o melhor dos mundos. O problema relacionado à liberdade do homem persiste, pois os caminhos humanos ainda são pré-determinados com a destruição de toda contingência, e o ataque de Arnauld à noção de possibilidades também permanece sem resposta.

\section{Contemplação, possibilidades e forma do ser}

Voltemos por isso a Descartes. Nele, como já dissemos, o mundo é criado a partir da vontade de Deus, que efetiva a criação por meio de sua onipotência. De acordo com Arnauld, só a partir de então algo pode se dar a conhecer à onisciência divina. Se olharmos para essa onisciência de Deus no ato da criação (Deus só contempla o mundo depois da criação), veremos que, por um lado, ela está confusamente misturada à vontade quando a Deus aparece o mundo que Ele deseja criar, e, por outro, ela é o conhecimento, a técnica pela qual Deus coloca seu poder em ação para efetivar o mundo: um saber fazer. Dessa forma a onisciência divina dilui-se na onipotência: num primeiro momento ela é um aspecto da vontade; e num segundo momento ela é uma etapa da onipotência. Deus é onipotente: essa é a fórmula condensada da essência de Deus em Descartes: a onisciência é esvaziada de qualquer positividade e submetida à onipotência.

A tal concepção da onisciência de Deus podemos chamar de instrumental, para contrapô-la à concepção mobilizada por Leibniz que chamaremos de contemplativa.

Voltando ao ato da criação, nos perguntamos: o que pode ser a onisciência de Deus diante do nada? Só pode ser consciência de si. Quando Arnauld, fiel às conclusões cartesianas, nega a Leibniz a existência de possibilidades antes da criação, ele baseia-se na absoluta esterilidade do nada, que não pode apresentar objeto algum a ser conhecido e muito menos variações sobre esse vazio. Mas, ao focar a atenção nessa anti-substância e seus atributos, Arnauld esquece-se de que, diante do nada, Deus é tudo. E esquece-se com isso do movimento fundamental da metafísica cartesiana: a reflexividade. Assim vemos a noção de possibilidades e a concepção contemplativa da onisciência de Deus brotarem de dentro dessa perspectiva que chamamos de instrumental: se a onisciência é um saber fazer, ela deve conhecer o poder infinito de Deus, ou seja, conhecer a extensão desse poder, tudo que Ele pode fazer. Se Deus pode criar infinitos mundos, Ele os contempla desde sempre diante de Si, donde Ele pode escolher - escolha que não foge à Sua natureza, à Sua vontade. Assim, se é absurdo que possam existir possibilidades independentes de Deus, como queria Arnauld, isso não implica que seja uma contradição a existência de possibilidades em absoluto, pois estas são fundadas no poder de Deus, na Sua onisciência e na Sua liberdade de escolha.

Também a forma do ser já é dada a Deus em si mesmo e a definição Dele como o ser onipotente, onisciente e infinitamente bom é desdobramento de uma outra: Deus é o ser que contém em grau último todos os atributos passíveis de um grau último (Leibniz 3, $\S 1$, p.119). Se o modo do ser é simultâneo a Deus, aqui o raciocínio de Arnauld se mostra correto: as possibilidades se desenham como variações de um ser dado. Considerar que Deus inventa o modo do ser a partir do nada é cair no absurdo de esquecer que Deus é $o$ Ser, e algo diferente disso só pode ser um não ser. Deve ser descartada por isso a possibilidade de outros parâmetros lógicos, como aqueles que admitiriam triângulos de 
ângulos internos com soma diferente de $180^{\circ}$, por exemplo. O que chamamos de lógico é o próprio regime do ser, e a impossibilidade lógica indica uma impossibilidade de fato, um não ser, algo que só tem expressão na linguagem, e não na realidade.

Se uma contradição lógica manifesta uma impossibilidade de fato, a razão humana não está apartada das coisas. Ela é análoga ao entendimento divino, embora limitada. Em Leibniz a razão dá acesso direto à verdade, e só sofre a restrição relativa ao seu ponto de vista finito. Como ser, o homem é análogo a Deus (Leibniz 3, §9, p.125).

\section{Contingência e determinação}

Tal como Deus, então, o homem é livre. Mas o livre arbítrio humano não se chocaria com a vontade de Deus? Pelo que vimos até agora, não. No parágrafo 13 do Discurso de Metafisica, Leibniz frisa que a partir de suas conclusões "Parece [...] destruir-se a diferença entre as verdades contingentes e necessárias, não haver lugar para a liberdade humana, e reinar sobre todas as nossas ações bem como sobre todos os restantes acontecimentos do mundo uma fatalidade absoluta. Contestarei isto pela afirmação da necessidade de distinguir o certo do necessário" (Leibniz 3, §13, p.124). Quando Deus estabelece o melhor dos mundos, o destino do mundo é certo e cada mônada já teve seu percurso previsto por Deus (Leibniz 3, §13, p.124). E essa certeza do percurso da mônada se deve à mesma razão de Deus ter que criar o melhor dos mundos: seu destino é nada mais que o desdobramento de seu ser. O que é diferente de uma necessidade lógica: o homem poderia agir de uma forma ou de outra, mas age manifestando seu ser. Por isso Leibniz afirma que "é absolutamente necessária só aquela [verdade] cujo contrário implique contradição; a outra é só necessária ex hypothesi, ou, por assim dizer, por acidente, mas é contingente em si mesma, quando o contrário não implique contradição" (Leibniz 3, §13, p.128-129). Um triângulo necessariamente tem ângulos internos que somam $180^{\circ}$, mas se Descartes usou um robe amarelo ou violeta ao escrever as Meditações é contingente, e só se funda na sua noção individual.

\section{Conclusão}

Desse modo, não há indeterminação no mundo. Mas isso não significa a eliminação da contingência e com ela a da liberdade. Como seres, tanto os homens como Deus agem de uma forma determinada, que é a forma com que eles são. O ser é: essa tautologia fica soterrada quando não nos damos conta de que o ser não é uma unidade estática e morta, de que há uma correspondência necessária entre o ser como substantivo e o ser como verbo. Sob outro ponto de vista, como formas, os seres não se reduzem a agregados de elementos mais simples e desprovidos de qualidades. É pela forma que Leibniz pode tomar partido da irredutibilidade da consciência (Leibniz 4, §13, p.106) sem tomá-la, no entanto, como uma simples negação de uma efetividade física que carregaria, assim, o status de maior evidência e, portanto, uma potencial precedência no processo do conhecimento. A realização completa da conclusão cartesiana de que o espiritual é mais fácil de conhecer que o corpóreo não poderia prescindir do tratamento desse espírito como absoluta positividade, em todos os seus aspectos. A forma como mônada propicia este tratamento, exorcizando seu caráter fantasmagórico de negação do corpóreo. Antes, é a própria efetividade física que não pode prescindir da unificação sob uma forma e leva à necessidade de considerar os indivíduos como substâncias, sob o perigo de o próprio corpóreo não se sustentar. Daí a grande necessidade que Leibniz vê em destacar a existência das causas finais, nos já referidos parágrafos 17 a 22 do Discurso de Metafísica, que nos levam a ver que a insistência num "paradigma" da causalidade eficiente como método suficiente de explicação do universo leva a uma explicação insuficiente tanto do objeto da física, como do objeto da metafísica, o que acaba por levar à oposição entre o que os sentidos captam e o que o pensamento na intuição de si mesmo estabelece. Sem a ponte entre esses dois domínios possibilitada pela noção de substância individual, essa oposição leva ao aparecimento de um como negação do outro, e a autonomia do espírito, pré-requisito para o conhecimento e a ação, perde a sua base em um ser positivo, detentor uma determinação precisa, para ser eternamente afiançada por um Deus que aprisiona a razão em um círculo.

Sob o ponto de vista da insubmissão da consciência à determinação do corpóreo, a recuperação de elementos das metafísicas pré-modernas não expressa um 
distanciamento de Leibniz do projeto da metafísica moderna anunciado em Descartes, mas sim uma afirmação. De acordo com o que examinamos, o distanciamento mais profundo de Leibniz em relação aos potenciais resultados da metafísica cartesiana é a respeito daquela submissão da bondade e onisciência divinas à onipotência, e à concepção cartesiana da vontade; ou seja, quanto aos resultados, a discordância de Leibniz em relação a Descartes se refletirá principalmente no terreno da ética. A própria maneira com que Leibniz frisa o papel da bondade na perfeição divina, contrastando com a definição de perfeição cartesiana que dá relevo à onipotência, onisciência e eternidade sem menção direta à bondade ${ }^{3}$ já aponta para essa preocupação, e todas as operações que afirmam a racionalidade das decisões divinas mostram que essa racionalidade não está desvinculada do imperativo ético.

\section{Leibniz on freedom of the being}

Abstract: In this paper we intend to verify the way in which Leibniz establishes a notion of liberty able to do not contradict the conception of a world in which all events are previously determined. Therefore, we are going to examine the way in which Leibniz can dissolve the opposition between determination and contingency of the events by means of notion of being as action. Furthermore, we are going to indicate aspects in which the Leibnizian project is opposed to the Cartesian dualism of substances and intends to overcome its dilemmas related both to Physics, in consequence of the complete passivity of res extensa, and to Metaphysics, above all in the aspects that res cogitans appears as a kind of denial of res extensa. Such a denial will imply the notion of will as pure arbitrariness, which rejects its regulation by any principle, and it will establish reason as an instrument of arbitrary will.

Keywords: contingency, will, being, omnipotence, form.

\section{REFERÊNCIAS BIBLIOGRÁFICAS:}

1. DESCARTES - Meditações. In: Descartes, Col. "Os Pensadores”, trad. Enrico Corvisieri, São Paulo: Nova Cultural, 1999

2. LACERDA, T. M. - A política da Metafísica: Teoria e Prática em Leibniz. São Paulo: Humanitas, 2005.

3. LEIBNIZ, G.W. - Discurso de Metafisica. In: Newton/Leibniz I, Col. “Os Pensadores”, trad. Marilena Chaui, São Paulo, Abril Cultural, 1979.

4. - Princípios da filosofia ou Monadologia. In: Newton/Leibniz I, Col. "Os Pensadores”, trad. Marilena Chaui, São Paulo, Abril Cultural, 1979.

5. - Escritos Filosóficos. trad. R. Torretti, T. E. Zwanck, E. Olaso. Buenos Aires: Editorial Charcas, 1982. - A correspondência entre Leibniz e Arnauld. trad. G. Müller Ayrosa, Dissertação de Mestrado: Universidade de São Paulo, 1993.

7. SANTOS, L. H. L. - "Leibniz e os futuros contingentes" in Analytica, Rio de Janeiro: vol. $3, \mathrm{n}^{\circ} 1,1998$.

\section{NOTAS:}

1 - Cf. Leibniz - Sobre la originación radical de las cosas Leibniz 5.

2 - A própria concepção da percepção em Leibniz blindaria o ser a qualquer forma de direção para outro. Perceber é simplesmente desdobrar-se, não envolvendo nenhuma concentração do ser em algo fora de si mesmo. O ser é identidade, tudo devendo ocorrer internamente a ele. Por fim, o ser deve realizar ontologicamente a forma perfeita de uma tautologia.

3 - "Pelo nome de Deus entendo uma substância infinita, eterna, imutável, independente, onisciente, onipotente [...].”(Descartes 1, p.228) 